\title{
Control of the immune response by pro-angiogenic factors
}

\section{Thibault Voron ${ }^{1}$, Elie Marcheteau ${ }^{1}$, Simon Pernot ${ }^{1,2}$, Orianne Colussi ${ }^{1,2}$, Eric Tartour ${ }^{1,3}$, Julien Taieb ${ }^{1,2}$ and Magali Terme ${ }^{1 *}$}

1 INSERM U970, PARCC (Paris Cardiovascular Research Center), Université Paris-Descartes, Sorbonne Paris Cité, Paris, France

${ }^{2}$ Service d'Hépatogastroentérologie et d'Oncologie Digestive, Hôpital Européen Georges Pompidou, Paris, France

${ }^{3}$ Service d'Immunologie Biologique, Hôpital Européen Georges Pompidou, Paris, France

\section{Edited by:}

Christian Stockmann, Institut National

de la Santé et de la Recherche

Médicale, France

Reviewed by:

Salem Chouaib, Institut Gustave

Roussy, France

Graham Robert Leggatt, University of

Carlos Alfaro, Clínica Universidad de

Navarra, Spain

*Correspondence:

Magali Terme, INSERM U970, PARCC

(Paris Cardiovascular Research

Center), Université Paris-Descartes,

Sorbonne Paris Cité, 56 rue Leblanc,

Paris 75015, France

e-mail: magali.terme@inserm.fr
Queensland, Australia

The progressive conversion of normal cells into cancer cells is characterized by the acquisition of eight hallmarks. Among these criteria, the capability of the cancer cell to avoid the immune destruction has been noted. Thus, tumors develop mechanisms to become invisible to the immune system, such as the induction of immunosuppressive cells, which are able to inhibit the development of an efficient immune response. Molecules produced in the tumor microenvironment are involved in the occurrence of an immunosuppressive microenvironment. Recently, it has been shown that vascular endothelial growth factor $A$ (VEGF-A) exhibits immunosuppressive properties in addition to its pro-angiogenic activities. VEGF-A can induce the accumulation of immature dendritic cells, myeloid-derived suppressor cells, regulatory $T$ cells, and inhibit the migration of T lymphocytes to the tumor. Other pro-angiogenic factors such as placental growth factor (PIGF) could also participate in tumorinduced immunosuppression, but only few works have been performed on this point. Here, we review the impact of pro-angiogenic factors (especially VEGF-A) on immune cells. Antiangiogenic molecules, which target VEGF-ANEGFR axis, have been developed in the last decades and are commonly used to treat cancer patients. These drugs have anti-angiogenic properties but can also counteract the tumor-induced immunosuppression. Based on these immunomodulatory properties, anti-angiogenic molecules could be efficiently associated with immunotherapeutic strategies in preclinical models. These combinations are currently under investigation in cancer patients.

Keywords: pro-angiogenic factors, VEGF-A, PIGF, tumor, immunosuppression, regulatory T cells, MDSC, immunotherapy

\section{INTRODUCTION}

Tumorigenesis is a multistep process in which a succession of genetic alterations, conferring some proliferative advantages, leads to the progressive conversion of normal cells into cancer cells. In 2000, Hanahan and Weinberg have grouped these genetic alterations into six distinctive and complementary biologic capabilities that constitute the six hallmarks criteria of cancer (1). They include sustaining proliferative signaling, evading growth suppressors, resisting cell death, enabling replicative immortality, activating invasion and metastasis, and inducing angiogenesis. Although these hallmarks criteria are mainly due to the accumulation of cell-intrinsic modifications, emerging evidences suggest that "tumor microenvironment," i.e., cells infiltrating the tumors and molecules produced inside, contributes also to the biology of many cancers. In the light of this new concept, Hanahan and Weinberg have revisited their criteria in 2011 and added two emerging criteria: deregulating cellular energetics and avoiding immune destruction (2).

The concept that the immune system can recognize and destroy cancer cells and so repress the development of tumor has first been described in 1909 by Paul Erhlich and then rephrased in 1957 by Sir MacFarlane Burnet and Lewis Thomas in the cancer immunosurveillance hypothesis (3-5). Nevertheless, this hypothesis was definitively accepted recently with studies highlighting the role of the immune system in controlling cancer development in animal models and in immunodeficient or immunosuppressed patients. Thus, Shankaran et al. have demonstrated that mice deficient for $\mathrm{T}$ and $\mathrm{B}$ lymphocytes (RAG2 ${ }^{-1-}$ mice) or mice deficient for interferon gamma signaling develop more frequently spontaneous cancer and carcinogen-induced cancer than wild type mice (6). In humans, immunodeficient or immunosuppressed patients had a higher incidence of cancer of non-viral origin (colon, lung, pancreas, melanoma) than immunocompetent patients (7-10). In addition, some immunosuppressed transplant recipients have been observed to develop tumor derived from the donor organ, underlining the importance of the immune system as an effective barrier to the tumor progression $(11,12)$. Finally, recent works have demonstrated that tumor infiltration by different immune cells (NK or T cells) was correlated with good prognosis in various cancers (13). For example, in colorectal cancer, Pagès and Galon have demonstrated that the absence of pathological signs of early metastatic invasion (vascular emboli, lymphatic invasion, and perineural invasion) was correlated with the presence of effector memory $\mathrm{T}$ cells $\left(\mathrm{CD} 45 \mathrm{RO}^{+}\right)$within the tumor and a better overall and disease-free survival (14). The density of T cells $\left(\mathrm{CD}^{+}\right)$infiltrating the tumor was also correlated with the outcome and seems to have a better and independent prognostic value for overall survival than the usual histopathologic prognostic 
factor (UICC-TNM classification) (15). Thus, to become clinically detectable in the immunocompetent host, cancer cells have to bypass this immunosurveillance by downregulating expression of molecules that are involved in immune recognition or by engendering a state of immunosuppression linked to the recruitment of immunoregulatory cells within the tumor or the production of immunosuppressive factors.

Recently, accumulative evidence suggests that pro-angiogenic factors could induce tumor growth and metastasis, not only by promoting angiogenesis but also by favoring this immunosuppressive microenvironment.

A better knowledge of this link between angiogenesis and immune escape could lead investigators to devise new therapeutic strategies combining anti-angiogenic therapy and immunotherapy.

\section{PRO-ANGIOGENIC FACTORS PROMOTE INTRATUMORAL IMMUNOSUPPRESSIVE MICROENVIRONMENT}

Angiogenesis, which is defined by the sprouting of new vessels from pre-existing ones, is a dynamic process that is observed under physiological conditions (embryogenesis and wound healing) but also under pathological conditions as tumor progression. In contrast with physiological angiogenesis that is transiently activated, pathological angiogenesis is almost always activated and remains on, resulting from a permanent imbalance between pro-angiogenic and anti-angiogenic factors. The absence of oxygen in the center of the tumor induces a hypoxic stress, which plays a key role in the regulation of angiogenesis. Hypoxia induces the stabilization and nuclear accumulation of the hypoxia-inducible factor (HIF), transcriptional factors, which results in the production of many pro-angiogenic factors including vascular endothelial growth factor A (VEGF-A) (16). VEGF-A plays a central role in inducing tumor angiogenesis. VEGF-A is a glycoprotein $(45 \mathrm{kDa})$ that is produced by nearly all tumor cells (17) and is found at elevated levels in the serum of cancer patients (18). It binds to two key receptors, VEGFR1 (Flt-1) and VEGFR2 (Flk-1, KDR), and one co-receptor (Neuropilin-1) to exert its pro-angiogenic activities. Although VEGF-A was initially identified as an endothelial cellspecific growth factor, it has become increasingly apparent that the functions of VEGF-A were more extensive, and especially act on immunity. Other pro-angiogenic factors like placental growth factor (PlGF) can also modulate intratumoral immunosuppressive microenvironment. PlGF is a member of the VEGF family, which is produced by tumor cells and stromal cells. It binds to VEGFR1 and induces migration and maturation of blood vessels by favoring proliferation, migration, and survival of endothelial cells. PlGF is correlated to tumor stage, to metastatic invasion, and inversely to survival in different solid tumors (19). PlGF also exhibits immunomodulatory properties (20). VEGF receptors can be expressed on endothelial cells, tumor cells, and some immune cells (21-23). VEGFR1 binds VEGF-A with higher affinity than VEGFR2 does, but VEGFR1 has a poor tyrosine kinase activity. Signaling pathways involved in VEGFR1 are confused. VEGFR1 may form heterodimers with VEGFR2 on endothelial cells as a consequence of VEGF-A binding and may also function as a decoy receptor sequestering VEGF-A from VEGFR2. But VEGFR1 may also transduce signals resulting in activation of proliferation, migration of the cells by activating Erk/MAPkinases, PI3K/Akt, PLC $\gamma$, and p38/MAPkinases (Figure 1) (24). VEGFR2 activation induces many biological responses such as proliferation, migration, survival by activation of PLC $\gamma$, Raf-kinases, and PI3K pathways (Figure 1).

\section{VEGF AND PLGF INHIBIT DENDRITIC CELL MATURATION}

Mature DCs are critical elements of anti-tumor immunity since professional antigen-presenting cells (APC) are responsible for the presentation of tumor-specific antigens and the triggering of an adaptive immune response mediated by T-cells (25). Conversely, in tumor-bearing mice (26) and cancer patients, differentiation and maturation of DC are impaired. Thus, immature DCs are not able to efficiently present tumor antigens to naive T-cells and therefore promote immune tolerance. The increase of the proportion of immature DC in the peripheral blood is correlated with the stage of the disease in cancer patients and is partially corrected by surgery, suggesting that this phenomenon is linked to a tumor-derived factor (27). The proportion of immature DC in the blood of cancer patients is closely associated with an increased VEGF-A plasma level. In mouse models, different studies have shown that VEGF-A binding to VEGFR1 blocks the activation of the transcriptional factor NF- $\kappa \mathrm{B}$ (nuclear factor- $\kappa \mathrm{B}$ ) and leads to inhibit DC maturation $(28,29)$. According with these results, PlGF, which binds specifically to VEGFR1, can also modulate DC differentiation, through the same mechanism $(20,30)$. In an in vitro model of dendritic cell differentiation from embryonic stem cells exposed to VEGF-A, Dikov et al. showed that VEGFR1 is involved in the inhibition of the final maturation of DC and VEGFR2 affects the differentiation of DC from early hematopoietic progenitors (20). Another in vitro study has shown that VEGF-A can alter the differentiation of monocytes into DC, effect reversed by anti-VEGF-A (bevacizumab) or sorafenib, an anti-angiogenic molecule targeting different receptors (VEGFR, PDGFR, and Rafkinases) (31). Administration of exogenous VEGF-A to tumor-free mice using osmotic pumps to mimic the VEGF concentrations observed in advanced cancer patients also blocks the ability of DC to stimulate allogeneic T-cell proliferation (32). Altogether, these results provide strong evidence that pro-angiogenic factor can inhibit DC maturation through both VEGFR1 and VEGFR2 pathways.

\section{PRO-ANGIOGENIC FACTORS FAVOR THE ACCUMULATION OF IMMUNOREGULATORY CELLS (MDSC, Treg, TUMOR-ASSOCIATED MACROPHAGES, Tie-2+ MONOCYTES)}

Myeloid-derived suppressor cells (MDSC) are a heterogeneous group of cells of myeloid origin, including myeloid progenitor cells and immature myeloid cells (macrophages, granulocytes, and dendritic cells) with immunosuppressive properties. MDSC accumulation in the tumor microenvironment leads to suppress T-cell response in different ways. MDSCs can first metabolize L-Arginine, an essential amino-acid for adult mammals that is required for Tcell proliferation $(33,34)$ : (i) using Arginase1, which results in a reduction of extra-cellular levels of L-Arginine (35); (ii) using the iNOS enzyme, which results in the generation of NO. The accumulation of NO in the tumor microenvironment blocks the proliferation of $\mathrm{T}$ cells and induces their apoptosis resulting in a decrease 


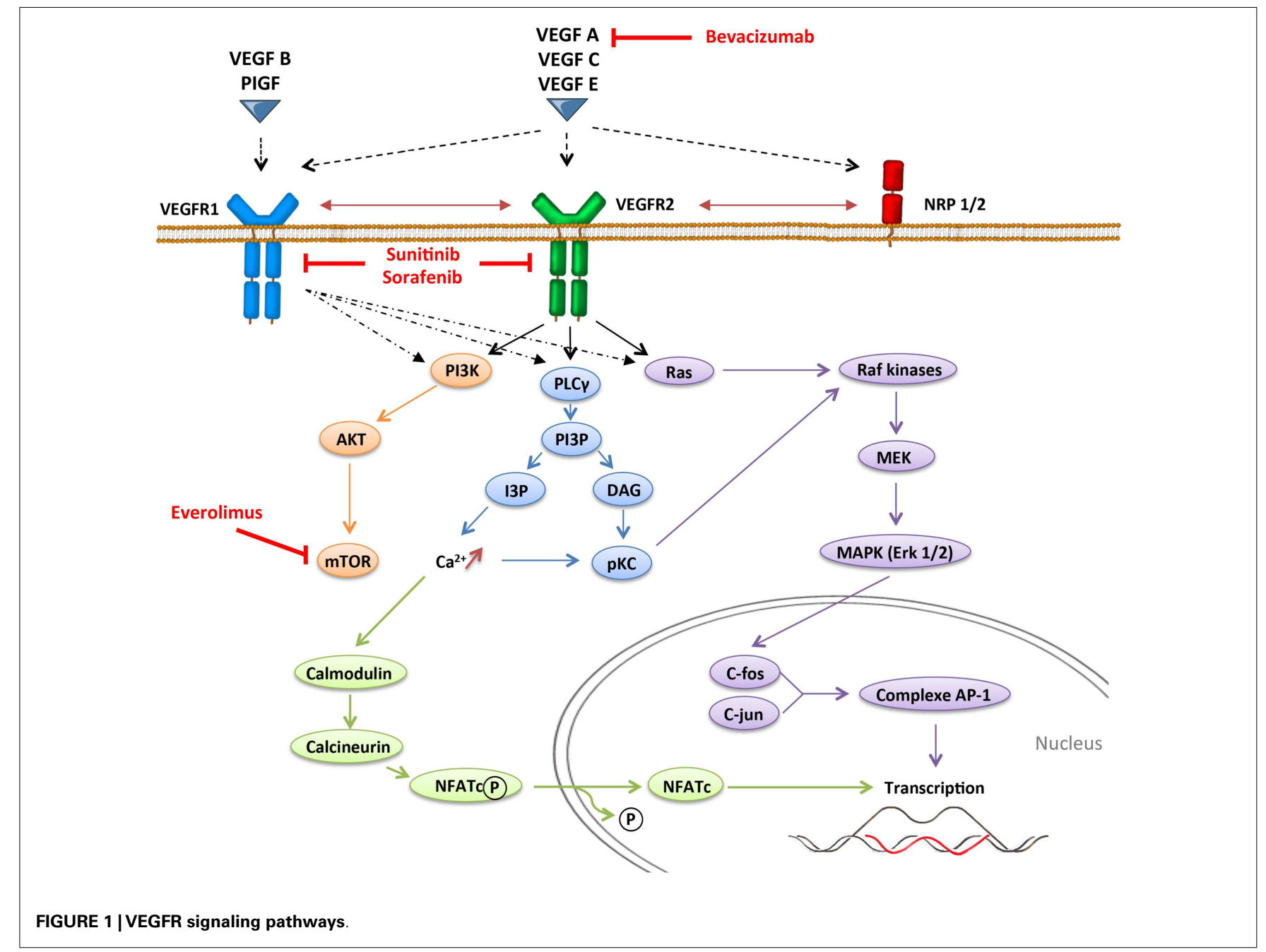

of tumor-infiltrating T-cells $(36,37)$. MDSCs can also exert their immunosuppressive properties by producing indoleamine 2,3dioxygenase, reactive oxygen species (ROS), like radical superoxide $\left(\mathrm{O}^{2} \bullet-\right)(38)$. Finally, reactivity between radical superoxide $\left(\mathrm{O}^{2} \bullet-\right)$ and NO, both produced by MDSC, leads to the formation of free radical peroxynitrite in the tumoral microenvironment that blocks the ability of $\mathrm{T}$ cells to recognize specific peptide/MHC complexes and perform their anti-tumor activity. MDSC can also control NK cell activation through membrane-bound TGF $\beta$ and $\mathrm{NKp} 30$ in an orthotopic mouse model of liver cancer and in hepatocellular carcinoma-bearing mice, respectively $(39,40)$. VEGF-A can promote the accumulation of MDSC (41). Indeed, Almand et al. reported an increase of MDSC in cancer patients, that is, associated with a decrease of mature DC. This accumulation is correlated with the disease stage and serum VEGF-A levels $(27,42)$. Moreover, an increase of $\mathrm{Gr} 1^{+} \mathrm{CD}_{1} 1 \mathrm{~b}^{+}$cells (MDSC) in the spleen of tumor-free mice treated with VEGF-A compared with control mice has been observed, and this effect is mediated by VEGFR2 (32) and activation of JAK2 (JAnus Kinase 2) and the transcription factor STAT3 (signal transducer and activator of transcription 3) downstream (43).
Pro-angiogenic factors could also contribute to other immunosuppressive cell accumulation such as regulatory $\mathrm{T}$ cell (Treg) in tumor-bearing hosts through direct or indirect mechanisms. Thus, MDSC, which are enhanced by VEGF, could induce de novo development of other immunosuppressive cells as of Foxp $3^{+}$Tregs through a TGF- $\beta$-dependent $(44,45)$ and/or independent pathway (46). Thus, in a mouse model of colon carcinoma, Gr1 ${ }^{+} \mathrm{CD} 115^{+}$ MDSC were shown to mediate the development of Treg by producing IL-10 and TGF- $\beta$ (44). Immature DC can also induce Treg differentiation and proliferation in a TGF $\beta$-dependent manner (47). Moreover, we have recently shown that VEGF-A, could also directly induce Treg proliferation in tumor-bearing mice and metastatic colorectal patients in a VEGFR2-dependent manner (22). Analysis of VEGFR expression on Tregs shows that Tregs express VEGFR2 only in tumor-bearing hosts but not in tumor-free mice (22).

Tumor-associated macrophages (TAM), which are correlated with poor prognosis (48-51), are induced by VEGF-A. But its development also needs the action of other cytokines produced by the tumor such as IL-10 and IL-4 (52). Another pro-angiogenic factor, angiopoietin-2 has also an impact on immune cells. 


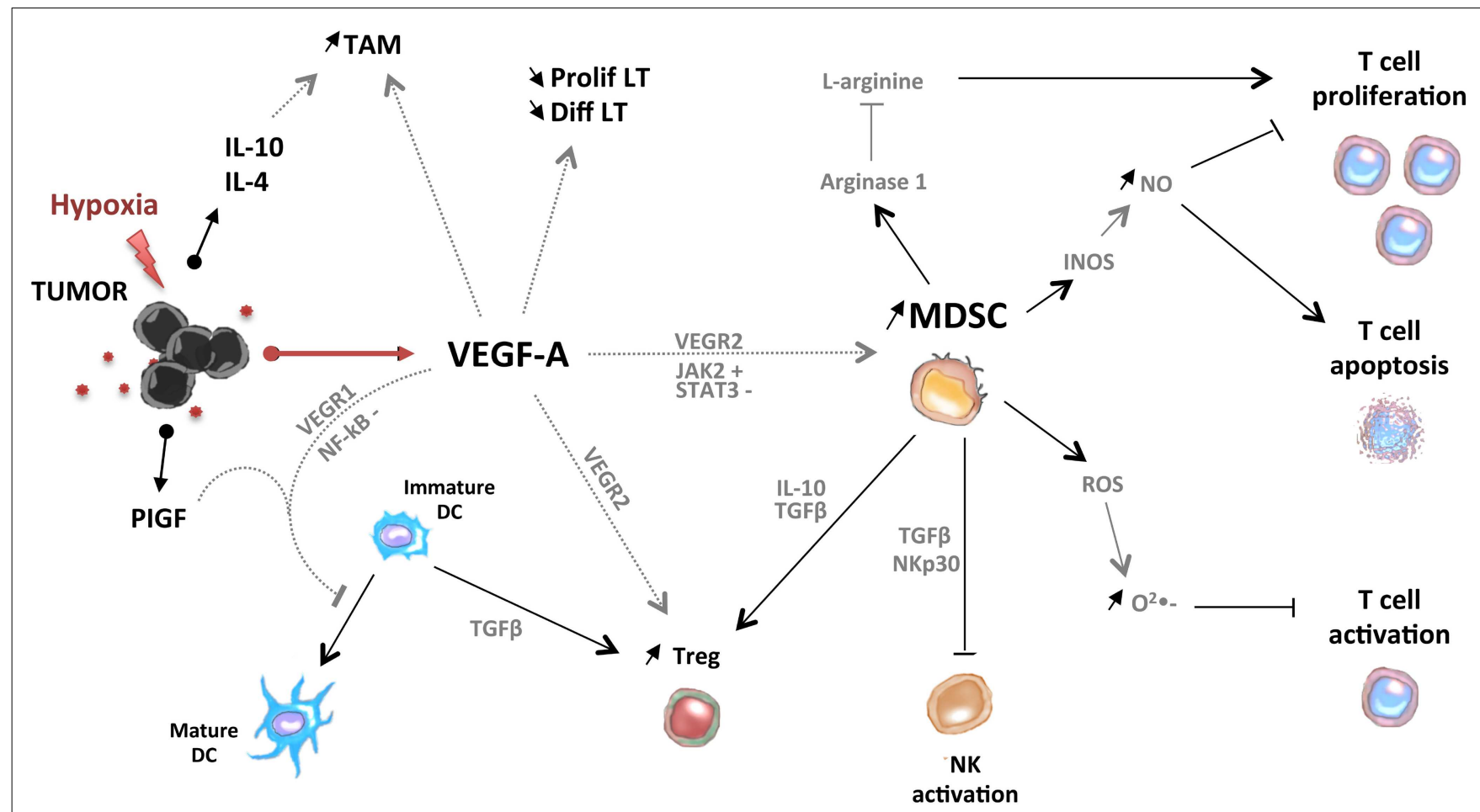

FIGURE 2 | Pro-angiogenic factors induce the development of an immunosuppressive state in tumors. VEGF-A induces the accumulation of MDSC, immature DC, Treg, and tumor-associated macrophages (TAM). MDSC and Treg are able to control activation of T cells and NK cells.

Angiopoietin-2 induces the release of IL-10 by Tie-2-expressing monocytes. Expression of angiopoietin-2 by tumor cells induces the recruitment of Tie-2-expressing monocytes in the tumor and the release of IL-10 by the cells $(53,54)$. IL-10 production by Tie-2expressing monocytes suppresses $\mathrm{T}$-cell proliferation, increases the ratio of $\mathrm{CD} 4^{+} \mathrm{T}$ cells to $\mathrm{CD} 8^{+} \mathrm{T}$ cells, and promotes the expansion of $\mathrm{CD} 4^{+} \mathrm{CD} 25^{\text {hi }} \mathrm{FOXP} 3^{+}$Tregs (53).

In conclusion, pro-angiogenic factors could contribute to the accumulation of immunosuppressive cells (MDSC, Treg, TAM, and Tie-2-expressing monocytes) in tumor-bearing hosts through direct or indirect mechanisms (Figure 2).

\section{PRO-ANGIOGENIC FACTORS AND CONVENTIONAL T CELLS}

Vascular endothelial growth factor A could inhibit the production of $\mathrm{T}$ cells, which are the major immune effector cells, by interfering with their development in thymus, as described by $\mathrm{Ohm}$ et al. (55). In this study, administration of exogenous VEGF-A to tumor-bearing mice at concentrations similar to those observed in advanced stage cancer patients leads to profound thymic atrophy, as observed in childhood malignancies, with a decrease in thymocyte cellularity. This inhibition of thymocyte maturation is caused through VEGFR2 pathway (32).

There are evidences for circulating T-cells in the periphery of tumor-bearing mice $(56,57)$ and cancer patients $(58,59)$, which are yet unable to control tumors (60). Thus, tumor angiogenesis, driven by pro-angiogenic factors, leads to the formation of a new vasculature that is structurally and functionally abnormal. New vessels are dilated, tortuous, and saccular, with disorganized and heterogeneous interconnections, resulting in hyperpermeable and insufficient vessels that could contribute to impediment of T cells extravasation. This hypothesis is reinforced with the recent work of Hamzah et al. using a genetically modified model of spontaneous pancreatic islet carcinoma in which the inactivation of Rgs5 (Regulator of G-protein signaling 5), a master gene controlling the aberrant morphology of tumor vasculature in mice and expressed by pericytes in the vascular bed, leads to normalization of tumors vessels (61). In this model where Rgs5 is inactivated, adoptive $\mathrm{T}$-cell transfer results in massive infiltration of $\mathrm{CD}^{+}$and $\mathrm{CD}^{+}$lymphocytes within the tumor, whereas wild type tumors showed no significant increase of intratumoral immune cells. In another model, overexpression of the histidine-rich glycoprotein (HRG) induces tumor vessels normalization through a down regulation of PlGF, and at the same time, leads to an increase of $\mathrm{CD}^{+}$lymphocyte infiltration within the tumor (62). Taken together, these results show a direct link between tumor vasculature normalization and enhanced immune cell infiltration.

Vascular endothelial growth factor A has also been shown to decrease effector functions (proliferation and cytotoxicity) of $\mathrm{T}$ lymphocytes obtained from peripheral blood and ascites of ovarian cancer patients $(63,64)$.

On the other hand, exposure of tumor cells to hypoxia prevents cytotoxic T lymphocyte (CTL)-mediated lysis of tumor cells (65). This phenomenon depends on hypoxia-induced VEGF-A since VEGF-A neutralization restores the susceptibility of tumor cells to CTL lysis and also on STAT3 activation. 
Thus, VEGF-A can induce an immunosuppressive microenvironment by targeting immune cells but also tumor cells.

\section{ANTI-ANGIOGENIC THERAPY CAN REVERSE IMMUNOSUPPRESSION}

Anti-angiogenic molecules have been developed to inhibit a major hallmark of cancer: angiogenesis. These treatments target preferentially the VEGF pathway since it has been revealed as a key regulator of angiogenesis, and include three types of VEGF-targeted agents: neutralizing antibodies to VEGF or VEGF receptors (like bevacizumab), tyrosine kinase inhibitors (TKI) that block intracellular signaling pathway (like sunitinib that targets VEGFR1-3, PDGFR, c-kit, and Flt3, or sorafenib that targets VEGFR1-3, PDGFR, c-kit, and Raf-kinases), and inhibitors of the mTOR pathway (like temsirolimus and everolimus) (Figure 1). The use of this VEGF-targeted therapy has been approved for metastatic colorectal cancer (66), hepatocellular carcinoma (67), clear-cell renal carcinoma (68), breast cancer (69), and non-small-cell lung carcinoma (70), alone or in combination with chemotherapy. These treatments can impact multiple pathways, act on tumor and endothelial cells, and block the neoangiogenesis. But they can also modulate other cells especially cells expressing VEGFR. According with the results presented above on the impact of pro-angiogenic factors on immunity, recent data suggest that anti-angiogenic therapy could reverse some immunosuppressive mechanisms involved in tumor escape and tumor growth and lead to improve cancer immunosurveillance.

\section{VEGF-TARGETED THERAPY MODULATES NUMBER AND FUNCTIONS OF IMMUNOSUPPRESSIVE CELLS}

Gabrilovich et al. have shown that anti-VEGF antibody significantly enhances the maturation of DC, resulting in an increase of number and functions of lymph nodes and spleen DCs in tumor-bearing mice treated with anti-VEGF-A (71). Osada has then confirmed this result in humans by demonstrating an increase in the number of DCs in peripheral blood and an improvement of DCs functions in advanced solid cancer patients treated with bevacizumab (anti-VEGF-A) (72). Blockade of VEGF-A pathway by anti-VEGF-A antibody in tumor-bearing mice also leads to a significant reduction of MDSCs in peripheral blood, as compared with untreated mice (73). Similarly, a decrease in the absolute number of MDSC in the spleen, bone marrow, and tumor in different tumor models (the MCA26 colorectal cancer, or the Renca renal cancer), has also been observed after treatment with sunitinib $(74,75)$. Furthermore, this decrease was associated with a reduction of immunosuppressive activity in vitro of MDSCs from sunitinib-treated mice, compared with MDSC from PBS-treated control mice (74). Inhibition of VEGF-A pathway could explain its activity on MDSCs since anti-VEGF antibody decreases a CD11 $\mathrm{b}^{+}$ VEGFR $1^{+}$subset of MDSC that is able to suppress T-cell response (73) but Xin et al. have also demonstrated that sunitinib could act on MDSCs by inhibiting Stat3 (75). Analysis of the impact of sunitinib on MDSC reveals that it inhibits the proliferation of the monocytic subset of MDSC $\left(\mathrm{Grl}^{\mathrm{lo}}\right)$ and induces the apoptosis of the granulocytic subset $\left(\mathrm{Grl}^{\mathrm{hi}}\right)$ (75). Treatment with sorafenib in a mouse model of liver tumor leads also to a decrease in MDSC levels in the spleen and bone marrow (76). Since MDSC levels in the peripheral blood of patients with head and neck cancer, nonsmall-cell lung cancer, breast cancer are positively correlated with plasma level of VEGF-A, VEGF-targeted therapy could induce a decrease of MDSCs in peripheral blood of cancer patients (27). In metastatic renal cell carcinoma patients, treatment with sunitinib decreases the percentage of MDSCs in peripheral blood, after one cycle of treatment $5.42 \%$ of PBMC before treatment vs. $2.28 \%$ after one cycle; $p=0.007)$, but also after the second cycle ( 2.28 vs. $1.29 \% ; p=0.02)(77)$.

Vascular endothelial growth factor-targeted therapy can also decrease Treg, either by inhibiting accumulation of MDSCs and immature DC in tumor microenvironment or directly through VEGF/VEGFR pathway inhibition on Treg. Thus, we have demonstrated recently that treatment of CT26 colorectal tumor-bearing mice with sunitinib or anti-VEGF-A antibody reduces the percentage and the absolute number of Treg in the spleen and tumor as compared with non-treated tumor-bearing mice (22). In the same manner, treatment with other anti-angiogenic therapies, such as sunitinib and sorafenib, modulates accumulation of Treg in tumor and spleen of various mouse tumor models $(22,76,78,79)$. Different mechanisms of sunitinib action have been proposed: (i) Treg decrease could be associated to the reduction of MDSC (77); (ii) a blockade of conversion of conventional $\mathrm{CD} 4^{+} \mathrm{Foxp}^{-} \mathrm{T}$ cells into regulatory $\mathrm{CD}^{+}{ }^{+} \mathrm{Foxp}^{+} \mathrm{T}$ cells (80); (iii) a reduction of the proliferation of pre-existing Tregs (22). In cancer patients, antiangiogenic treatments also reduce Tregs in periphery. Sunitinib treatment decreases the number of Foxp $3^{+}$Tregs in the peripheral blood of metastatic renal cancer patients (79) and this decrease was positively correlated with a better overall survival $(81,82)$. Similarly, sorafenib treatment induces a reduction in regulatory T-cell number in the peripheral blood of patients with hepatocellular carcinoma (83). Bevacizumab, which is used in association with chemotherapy as a first-line treatment in metastatic colorectal cancer patients, also decreases regulatory T-cell proportion in the peripheral blood of these patients. This decrease is linked to a reduction of Treg proliferation (22).

\section{ANTI-ANGIOGENIC MOLECULES AND CONVENTIONAL T CELLS}

Ozao-Choy et al. have demonstrated in tumor-bearing mice that sunitinib treatment enhances the percentage and number of intratumoral $\mathrm{CD}^{+}$and $\mathrm{CD}^{+}$T-cells compared with tumorbearing mice treated with PBS (74). Similarly, blockade of VEGFA/VEGFR2 pathway in tumor-bearing mice improves the infiltration of adoptively transferred $\mathrm{T}$ cells into the tumor and tumor regression (84). This better infiltration could be associated with the capacity of anti-angiogenic molecules to normalize tumor vasculature and probably to prevent loss of ICAM- 1 and VCAM-1 on endothelial cells (85). Sunitinib treatment can also modulate expression of inhibitory molecules on tumor-infiltrating $\mathrm{T}$ cells such as PD-1, CTLA-4 (74).

\section{IMPACT OF STRATEGY COMBINING ANTI-ANGIOGENIC THERAPY WITH IMMUNOTHERAPY}

Anti-angiogenic drugs have improved the treatment of many solid tumors. These molecules have anti-angiogenic impact but also immunomodulatory properties $(86,87)$. As described above, anti-angiogenic drugs inhibit the accumulation of 
immunosuppressive cells (immature myeloid cells such as immature dendritic cells and MDSC, Treg), which are able to inhibit the development of an efficient anti-tumor immune response. They can also enhance the proportion of tumor-infiltrating $\mathrm{T}$ lymphocytes probably by normalizing tumor vessels and by modulating the expression of adhesion molecules involved in T-lymphocyte extravasation (88). Sunitinib can also enhance the Th1 response of T lymphocytes derived from metastatic renal cancer patients after mitogen restimulation (81). However, they do not seem able to restore a spontaneous specific T-cell response to tumor antigens. Based on their immunomodulatory properties, anti-angiogenic drugs could be combined to immunotherapeutic strategies to obtain durable anti-tumor responses. Recently, immunotherapy has obtained successes, especially in the treatment of metastatic solid cancer patients, where anti-CTLA-4 or anti-PD1 antibodies administration results in an enhancement of the proportion of objective and durable responses $(89,90)$. Furthermore, Sipuleucel$\mathrm{T}$ is the first vaccination strategy approved by the FDA for the treatment of patient with castration-resistant prostate cancer. This vaccine induces an improvement of overall survival (91). The future of immunotherapy will probably involve combination with other immunomodulatory agents. Different groups tried to combine immunotherapeutic strategies with anti-angiogenic molecules in mouse tumor models. The most commonly used molecule in these studies is sunitinib. Association of sunitinib with adenoviral vectors encoding for IL-12 and other immunostimulating molecules or pox-virus encoding for stimulatory molecules and tumor antigen decreased tumor growth in different mouse models (colorectal cancer, hepatocellular carcinoma) (74, 92). To design relevant protocols of treatment with anti-angiogenic molecules and immunotherapy, it is necessary to determine the scheduling of drug administration. Administration of sunitinib before vaccination induced a superior anti-tumor efficacy than administration after vaccination or concurrently (92). A recent work has even shown that sunitinib administration concurrently with a vaccine against a tumor antigen results in a lack of reactivity against the tumor antigen in a mouse mammary tumor model. The strategy failure seems to be due to a transient loss of CD11 ${ }^{+}$ $\mathrm{CD}_{11} \mathrm{~b}^{+} \mathrm{APC}$ in the lymph nodes, which inhibits the priming of $\mathrm{T}$ lymphocytes (93). To optimize strategies combining antiangiogenic drugs to immunotherapy, we also need to determine which anti-angiogenic should be used and at which dosage. VEGFA/VEGFR2 targeted therapies seem to be the best choice, since they can modulate both Treg and MDSC. Administration of low-doses of anti-VEGFR2 antibody results in a transient vascular normalization and improves the $\mathrm{CD}^{+}$and $\mathrm{CD} 8^{+}$tumor infiltration. Association of low-doses of anti-VEGFR2 with whole cancer cell vaccine induces anti-tumor efficacy (94).

Interestingly in metastatic renal cancer, two patients received sunitinib before radical nephrectomy and dendritic cell therapy. These two patients displayed disease stabilization after sunitinib treatment and regression of metastatic lesions after nephrectomy and DC vaccine, suggesting that sunitinib could synergize with DC vaccine (95). In an open-label phase II trial, 21 metastatic renal cancer patients received sunitinib and a DC-based vaccine (AGS-003). This vaccine consists of mature monocyte-derived DC electroporated with mRNA harvested from the patient's tumor and synthetic CD40L mRNA. This combination resulted in an interesting progression-free survival and overall survival. An international phase 3 trial will be launched based on these results (NCT01582672). Other clinical trials are testing combination between anti-angiogenic drugs and immunotherapy in

Table 1 | Ongoing clinical trials, according to National Cancer Institute (NCI) registration, using association of anti-angiogenic drugs with immunotherapy.

\begin{tabular}{|c|c|c|c|c|c|}
\hline Anti-angiogenic & Immunotherapy & Cancer & Phase & Status & $\begin{array}{l}\text { Registration } \\
\text { number }\end{array}$ \\
\hline Bevacizumab & MK-3475 (anti-PD1) & $\begin{array}{l}\text { Locally advanced or metastatic } \\
\text { non-small-cell lung carcinoma }\end{array}$ & $|/| \mid$ & Recruiting & NCT02039674 \\
\hline Bevacizumab & MPDL3280A (anti-PDL1) & Advanced solid tumors & I & Recruiting & NCT01633970 \\
\hline Bevacizumab & Ipilimumab (anti-CTLA4) & Unresectable stage III or IV melanoma & I & Active, not recruiting & NCT00790010 \\
\hline Bevacizumab & Nivolumab (anti-PD1) & Stage IIIB/IV non-small-cell lung cancer & I & Recruiting & NCT01454102 \\
\hline Sunitinib & Nivolumab (anti-PD1) & Metastatic renal cell carcinoma & I & Active, not recruiting & NCT01472081 \\
\hline Bevacizumab & Dendritic cell immunotherapy & $\begin{array}{l}\text { Resected hepatic metastasis of colorectal } \\
\text { carcinoma }\end{array}$ & $\|$ & Recruiting & NCT01348256 \\
\hline Sunitinib & $\begin{array}{l}\text { Autologous dendritic cell } \\
\text { immunotherapy (AGS-003) }\end{array}$ & Advanced renal cell carcinoma & III & Recruiting & NCT01582672 \\
\hline Sorafenib & Interleukin 21 & Renal cell carcinoma & $|/| \mid$ & Completed (96) & NCT00389285 \\
\hline
\end{tabular}


cancer patients, especially association of antibodies targeting inhibitory immune checkpoints (anti-PD-1, anti-CTLA-4) with bevacizumab or sunitinib (Table 1 ).

\section{CONCLUSION}

Pro-angiogenic factors and especially VEGF-A modulate the tumor microenvironment. VEGF-A plays a key role in controlling tumor angiogenesis but also in modulating tumor-induced immunosuppression (accumulation of immature DC, MDSC, Treg). Anti-angiogenic drugs can decrease immunosuppression. However, these molecules are not able to reactivate efficient immune responses against the tumor. In this goal, association of anti-angiogenic molecules to immunotherapeutic strategies could be of major interest. Different preclinical models have shown that this combination can induce potent anti-tumor response. To optimize protocols of treatment with anti-angiogenic drugs and immunotherapeutic strategies, different parameters should be analyzed such as the scheduling of the treatment and the doses of anti-angiogenic drugs to administer.

\section{ACKNOWLEDGMENTS}

This work was supported by Roche, Pfizer, Association pour la Recherche contre le Cancer, Ligue contre le Cancer, and Association des Gastroentérologues Oncologues. Thibault Voron was supported by Association Benoit Malassagne, and Société Francaise de Chirurgie Digestive. Magali Terme was supported by the Site de Recherche Intégré sur le Cancer - Programme Cancer Research for Personalized Medicine (CARPEM), the Association des Gastroentérologues Oncologues, the Labex Immunooncology.

\section{REFERENCES}

1. Hanahan D, Weinberg R. The hallmarks of cancer. Cell (2000) 100:57-70. doi:10.1016/S0092-8674(00)81683-9

2. Hanahan D, Weinberg R. Hallmarks of cancer: the next generation. Cell (2011) 144(5):646-74. doi:10.1016/j.cell.2011.02.013

3. Thomas L. On immunosurveillance in human cancer. Yale J Biol Med (1982) 55(3-4):329-33.

4. Thomas L. Discussion on Cellular and Humoral Aspects of the Hypersensitive States. New York: Hoeber (1959). p. 529-32.

5. Burnet SM. Cancer - a biological approach. Br Med J (1957) 1(5023):779-86. doi:10.1136/bmj.1.5022.779

6. Shankaran V, Ikeda H, Bruce AT, White JM, Swanson PE, Old LJ, et al. IFNgamma and lymphocytes prevent primary tumour development and shape tumour immunogenicity. Nature (2001) 410(6832):1107-11. doi:10.1038/35074122

7. Gatti RA, Good RA. Occurrence of malignancy in immunodeficiency diseases. A literature review. Cancer (1971) 28(1):89-98. doi:10.1002/1097-0142(197107) 28:1<89::AID-CNCR2820280117>3.0.CO;2-Q

8. Birkeland SA, Storm HH, Lamm LU, Barlow L, Blohmé I, Forsberg B, et al. Cancer risk after renal transplantation in the Nordic countries, 1964-1986. Int J Cancer (1995) 60(2):183-9. doi:10.1002/ijc.2910600209

9. Penn I. Post-transplant malignancy: the role of immunosuppression. Drug Saf (2000) 23(2):101-13. doi:10.2165/00002018-200023020-00002

10. Penn I. Sarcomas in organ allograft recipients. Transplantation (1995) 60(12):1485-91. doi:10.1097/00007890-199560120-00020

11. MacKie RM, Reid R, Junor B. Fatal melanoma transferred in a donated kidney 16 years after melanoma surgery. N Engl J Med (2003) 348(6):567-8. doi:10.1056/NEJM200302063480620

12. Strauss DC, Thomas JM. Transmission of donor melanoma by organ transplantation. Lancet Oncol (2010) 11(8):790-6. doi:10.1016/S1470-2045(10)70024-3

13. Fridman WH, Pagès F, Sautès-Fridman C, Galon J. The immune contexture in human tumours: impact on clinical outcome. Nat Rev Cancer (2012) 12(4):298-306. doi:10.1038/nrc3245
14. Pagès F, Berger A, Camus M, Sanchez-Cabo F, Costes A, Molidor R, et al. Effector memory T cells, early metastasis, and survival in colorectal cancer. N Engl J Med (2005) 353(25):2654-66. doi:10.1056/NEJMoa051424

15. Galon J, Costes A, Sanchez-Cabo F, Kirilovsky A, Mlecnik B, Lagorce-Pagès $\mathrm{C}$, et al. Type, density, and location of immune cells within human colorectal tumors predict clinical outcome. Science (2006) 313(5795):1960-4. doi:10.1126/science.1129139

16. Chouaib S, Messai Y, Couve S, Escudier B, Hasmim M, Noman MZ. Hypoxia promotes tumor growth in linking angiogenesis to immune escape. Front Immunol (2012) 3(February):21. doi:10.3389/fimmu.2012.00021

17. Ferrara N, Davis-Smyth T. The biology of vascular endothelial growth factor. Endocr Rev (1997) 18(1):4-25. doi:10.1210/edrv.18.1.0287

18. Dvorak HF, Brown LF, Detmar M, Dvorak AM. Vascular permeability factor/vascular endothelial growth factor, microvascular hyperpermeability, and angiogenesis harold. Am J Pathol (1995) 146(5):1029-39.

19. Dewerchin M, Carmeliet P. PlGF: a multitasking cytokine with disease-restricted activity. Cold Spring Harb Perspect Med (2012) 2(8):a011056. doi:10.1101/ cshperspect.a011056

20. Dikov M, Ohm J, Ray N. Differential roles of vascular endothelial growth factor receptors 1 and 2 in dendritic cell differentiation. J Immunol (2005) 174:215-22.

21. Goel HL, Mercurio AM. VEGF targets the tumour cell. Nat Rev Cancer (2013) 13(12):871-82. doi:10.1038/nrc3627

22. Terme M, Pernot S, Marcheteau E, Sandoval F, Benhamouda N, Colussi $\mathrm{O}$, et al. VEGFA-VEGFR pathway blockade inhibits tumor-induced regulatory T-cell proliferation in colorectal cancer. Cancer Res (2013) 73(2):539-49. doi:10.1158/0008-5472.CAN-12-2325

23. Hansen W, Hutzler M, Abel S, Alter C, Stockmann C, Kliche S, et al. Neuropilin 1 deficiency on CD4+Foxp3+ regulatory T cells impairs mouse melanoma growth. J Exp Med (2012) 209(11):2001-16. doi:10.1084/jem.20111497

24. Koch S, Tugues S, Li X, Gualandi L, Claesson-Welsh L. Signal transduction by vascular endothelial growth factor receptors. Biochem J (2011) 437(2):169-83. doi:10.1042/BJ20110301

25. Banchereau J, Steinman RM. Dendritic cells and the control of immunity. Nature (1998) 392(6673):245-52. doi:10.1038/32588

26. Haux PC, Avre NF, Artin MM. Tumor-infiltrating dendritic cells are defective in their antigen-presenting function and inducible B7 expression in rats. Int J Cancer (1997) 624:619-24.

27. Almand B, Resser J, Lindman B. Clinical significance of defective dendritic cell differentiation in cancer. Clin Cancer Res (2000) 6(5):1755-66.

28. Gabrilovich DI, Chen HL, Girgis KR, Cunningham HT, Meny GM, Nadaf S, et al. Production of vascular endothelial growth factor by human tumors inhibits the functional maturation of dendritic cells. Nat Med (1996) 2(10):1096-103. doi:10.1038/nm1096-1096

29. Oyama T, Ran S, Ishida T, Nadaf S, Kerr L, Carbone DP, et al. Vascular endothelial growth factor affects dendritic cell maturation through the inhibition of nuclear factor-kappa B activation in hematopoietic progenitor cells. J Immunol (1998) 160(3):1224-32.

30. Lin Y-L, Liang Y-C, Chiang B-L. Placental growth factor down-regulates type $1 \mathrm{~T}$ helper immune response by modulating the function of dendritic cells. J Leukoc Biol (2007) 82(6):1473-80. doi:10.1189/jlb.0307164

31. Alfaro C, Suarez N, Gonzalez A, Solano S, Erro L, Dubrot J, et al. Influence of bevacizumab, sunitinib and sorafenib as single agents or in combination on the inhibitory effects of VEGF on human dendritic cell differentiation from monocytes. Br J Cancer (2009) 100(7):1111-9. doi:10.1038/sj.bjc. 6604965

32. Huang Y, Chen X, Dikov MM, Novitskiy SV, Mosse CA, Yang L, et al. Distinct roles of VEGFR-1 and VEGFR-2 in the aberrant hematopoiesis associated with elevated levels of VEGF. Blood (2007) 110(2):624-31. doi:10.1182/blood-200701-065714

33. Zea AH, Rodriguez PC, Culotta KS, Hernandez CP, DeSalvo J, Ochoa JB, et al. LArginine modulates CD3zeta expression and $\mathrm{T}$ cell function in activated human T lymphocytes. Cell Immunol (2004) 232(1-2):21-31. doi:10.1016/j.cellimm. 2005.01.004

34. Bronte V, Zanovello P. Regulation of immune responses by L-arginine metabolism. Nat Rev Immunol (2005) 5(8):641-54. doi:10.1038/nril668

35. Rodriguez PC, Quiceno DG, Ochoa AC. L-arginine availability regulates Tlymphocyte cell-cycle progression. Blood (2007) 109(4):1568-73. doi:10.1182/ blood-2006-06-031856 
36. Mazzoni A, Bronte V, Visintin A, Spitzer JH, Apolloni E, Serafini P, et al. Myeloid suppressor lines inhibit $\mathrm{T}$ cell responses by an NO-dependent mechanism. J Immunol (2002) 168(2):689-95.

37. Fischer TA, Palmetshofer A, Gambaryan S, Butt E, Jassoy C, Walter U, et al. Activation of cGMP-dependent protein kinase Ibeta inhibits interleukin 2 release and proliferation of T cell receptor-stimulated human peripheral T cells. J Biol Chem (2001) 276(8):5967-74. doi:10.1074/jbc.M009781200

38. Kusmartsev S, Nefedova Y, Yoder D, Gabrilovich DI. Antigen-specific inhibition of CD8+ T cell response by immature myeloid cells in cancer is mediated by reactive oxygen species. J Immunol (2004) 172(2):989-99.

39. Li H, Han Y, Guo Q, Zhang M, Cao X. Cancer-expanded myeloid-derived suppressor cells induce anergy of NK cells through membrane-bound TGF-beta 1 . J Immunol (2009) 182(1):240-9.

40. Hoechst B, Voigtlaender T, Ormandy L, Gamrekelashvili J, Zhao F, Wedemeyer $\mathrm{H}$, et al. Myeloid derived suppressor cells inhibit natural killer cells in patients with hepatocellular carcinoma via the NKp30 receptor. Hepatology (2009) 50(3):799-807. doi:10.1002/hep.23054

41. Gabrilovich D, Ishida T, Oyama T. Vascular endothelial growth factor inhibits the development of dendritic cells and dramatically affects the differentiation of multiple hematopoietic lineages in vivo. Blood (1998) 92:4150-66.

42. Almand B, Clark JI, Nikitina E, van Beynen J, English NR, Knight SC, et al. Increased production of immature myeloid cells in cancer patients: a mechanism of immunosuppression in cancer. J Immunol (2001) 166(1):678-89.

43. Nefedova Y, Huang M, Kusmartsev S, Bhattacharya R, Cheng P, Salup R, et al. Hyperactivation of STAT3 is involved in abnormal differentiation of dendritic cells in cancer. J Immunol (2004) 172(1):464-74.

44. Huang B, Pan P-Y, Li Q, Sato AI, Levy DE, Bromberg J, et al. Gr-1+CD115+ immature myeloid suppressor cells mediate the development of tumor-induced $\mathrm{T}$ regulatory cells and T-cell anergy in tumor-bearing host. Cancer Res (2006) 66(2):1123-31. doi:10.1158/0008-5472.CAN-05-1299

45. Yang R, Cai Z, Zhang Y, Yutzy WH, Roby KF, Roden RBS. CD80 in immune suppression by mouse ovarian carcinoma-associated Gr-1+CD11b+ myeloid cells. Cancer Res (2006) 66(13):6807-15. doi:10.1158/0008-5472.CAN-05-3755

46. Serafini P, Mgebroff S, Noonan K, Borrello I. Myeloid-derived suppressor cells promote cross-tolerance in B-cell lymphoma by expanding regulatory $\mathrm{T}$ cells. Cancer Res (2008) 68(13):5439-49. doi:10.1158/0008-5472.CAN-07-6621

47. Ghiringhelli F, Puig PE, Roux S, Parcellier A, Schmitt E, Solary E, et al. Tumor cells convert immature myeloid dendritic cells into TGF-beta-secreting cells inducing CD4+CD25+ regulatory $\mathrm{T}$ cell proliferation. J Exp Med (2005) 202(7):919-29. doi:10.1084/jem.20050463

48. Hanada T, Nakagawa M, Emoto A, Nomura T, Nasu N, Nomura Y. Prognostic value of tumor-associated macrophage count in human bladder cancer. Int J Urol (2000) 7(7):263-9. doi:10.1046/j.1442-2042.2000.00190.x

49. Lissbrant IF, Stattin P, Wikstrom P, Damber JE, Egevad L, Bergh A. Tumor associated macrophages in human prostate cancer: relation to clinicopathological variables and survival. Int J Oncol (2000) 17(3):445-51.

50. Salvesen HB, Akslen LA. Significance of tumour-associated macrophages, vascular endothelial growth factor and thrombospondin-1 expression for tumour angiogenesis and prognosis in endometrial carcinomas. Int J Cancer (1999) 84(5):538-43. doi:10.1002/(SICI) 1097-0215(19991022)84:5<538::AIDIJC17>3.3.CO;2-2

51. Leek RD, Lewis CE, Whitehouse R, Greenall M, Clarke J, Harris AL. Association of macrophage infiltration with angiogenesis and prognosis in invasive breast carcinoma. Cancer Res (1996) 56(20):4625-9.

52. Linde N, Lederle W, Depner S, van Rooijen N, Gutschalk CM, Mueller MM. Vascular endothelial growth factor-induced skin carcinogenesis depends on recruitment and alternative activation of macrophages. J Pathol (2012) 227(1):17-28. doi:10.1002/path.3989

53. Coffelt SB, Chen Y-Y, Muthana M, Welford AF, Tal AO, Scholz A, et al. Angiopoietin 2 stimulates TIE2-expressing monocytes to suppress $\mathrm{T}$ cell activation and to promote regulatory $\mathrm{T}$ cell expansion. J Immunol (2011) 186(7):4183-90. doi:10.4049/jimmunol.1002802

54. Lewis CE, Hughes R. Inflammation and breast cancer. Microenvironmental factors regulating macrophage function in breast tumours: hypoxia and angiopoietin-2. Breast Cancer Res (2007) 9(3):209. doi:10.1186/bcr1679

55. Ohm JE, Gabrilovich DI, Sempowski GD, Kisseleva E, Parman KS, Nadaf S, et al. VEGF inhibits T-cell development and may contribute to tumor-induced immune suppression. Blood (2003) 101(12):4878-86. doi:10.1182/blood-200207- 1956
56. Prévost-Blondel A, Zimmermann C, Stemmer C, Kulmburg P, Rosenthal FM, Pircher H. Tumor-infiltrating lymphocytes exhibiting high ex vivo cytolytic activity fail to prevent murine melanoma tumor growth in vivo. J Immunol (1998) 161(5):2187-94

57. Hermans I, Daish A, Yang J, Ritchie D, Ronchese F. Antigen expressed on tumor cells fails to elicit an immune response, even in the presence of increased numbers of tumor-specific cytotoxic T lymphocyte precursors. Cancer Res (1998) 58(17):3909-17.

58. Lee PP, Yee C, Savage PA, Fong L, Brockstedt D, Weber JS, et al. Characterization of circulating $\mathrm{T}$ cells specific for tumor-associated antigens in melanoma patients. Nat Med (1999) 5(6):677-85. doi:10.1038/9525

59. Romero P, Dunbar P, Valmori D. Ex vivo staining of metastatic lymph nodes by class i major histocompatibility complex tetramers reveals high numbers of antigen-experienced tumor-specific cytolytic T lymphocytes. J Exp Med (1998) 188(9). doi:10.1084/jem.188.9.1641

60. Rosenberg SA, Sherry RM, Morton KE, Scharfman WJ, Yang JC, Topalian SL, et al. Tumor progression can occur despite the induction of very high levels of self/tumor antigen-specific CD8+ T cells in patients with melanoma. J Immunol (2005) 175(9):6169-76.

61. Hamzah J, Jugold M, Kiessling F, Rigby P, Manzur M, Marti HH, et al. Vascular normalization in Rgs5-deficient tumours promotes immune destruction. Nature (2008) 453(7193):410-4. doi:10.1038/nature06868

62. Rolny C, Mazzone M, Tugues S, Laoui D, Johansson I, Coulon C, et al. HRG inhibits tumor growth and metastasis by inducing macrophage polarization and vessel normalization through downregulation of PlGF. Cancer Cell (2011) 19(1):31-44. doi:10.1016/j.ccr.2010.11.009

63. Ziogas AC, Gavalas NG, Tsiatas M, Tsitsilonis O, Politi E, Terpos E, et al. VEGF directly suppresses activation of T cells from ovarian cancer patients and healthy individuals via VEGF receptor Type 2. Int J Cancer (2012) 130(4):857-64. doi:10.1002/ijc.26094

64. Gavalas NG, Tsiatas M, Tsitsilonis O, Politi E, Ioannou K, Ziogas AC, et al. VEGF directly suppresses activation of $\mathrm{T}$ cells from ascites secondary to ovarian cancer via VEGF receptor type 2. Br J Cancer (2012) 107(11):1869-75. doi:10.1038/bjc.2012.468

65. Noman MZ, Buart S, Van Pelt J, Richon C, Hasmim M, Leleu N, et al. The cooperative induction of hypoxia-inducible factor- 1 alpha and STAT3 during hypoxia induced an impairment of tumor susceptibility to CTLmediated cell lysis. J Immunol (2009) 182(6):3510-21. doi:10.4049/jimmunol. 0800854

66. Hurwitz H, Fehrenbacher L, Novotny W, Cartwright T, Hainsworth J, Heim W, et al. Bevacizumab plus irinotecan, fluorouracil, and leucovorin for metastatic colorectal cancer. N Engl J Med (2004) 350(23):2335-42. doi:10.1056/ NEJMoa032691

67. Llovet J, Ricci S. Sorafenib in advanced hepatocellular carcinoma. N Engl J Med (2008) 359(4):378-90. doi:10.1056/NEJMoa0708857

68. Escudier B, Eisen T, Stadler WM, Szczylik C, Oudard S, Siebels M, et al. Sorafenib in advanced clear-cell renal-cell carcinoma. N Engl J Med (2007) 356(2):125-34. doi:10.1056/NEJMoa060655

69. Miller K, Wang M, Gralow J, Dickler M, Cobleigh M, Perez EA, et al. Paclitaxel plus bevacizumab versus paclitaxel alone for metastatic breast cancer. $N$ Engl J Med (2007) 357(26):2666-76. doi:10.1056/NEJMoa072113

70. Sandler A, Gray R, Perry MC, Brahmer J, Schiller JH, Dowlati A, et al. Paclitaxelcarboplatin alone or with bevacizumab for non-small-cell lung cancer. $N$ Engl J Med (2006) 355(24):2542-50. doi:10.1056/NEJMoa061884

71. Gabrilovich D, Ishida T, Nadaf S. Antibodies to vascular endothelial growth factor enhance the efficacy of cancer immunotherapy by improving endogenous dendritic cell function. Clin Cancer Res (1999) 5:2963-70.

72. Osada T, Chong G, Tansik R, Hong T, Spector N, Kumar R, et al. The effect of anti-VEGF therapy on immature myeloid cell and dendritic cells in cancer patients. Cancer Immunol Immunother (2008) 57(8):1115-24. doi:10.1007/ s00262-007-0441-x

73. Kusmartsev S, Eruslanov E, Kübler H, Tseng T, Sakai Y, Su Z, et al. Oxidative stress regulates expression of VEGFR1 in myeloid cells: link to tumorinduced immune suppression in renal cell carcinoma. J Immunol (2008) 181: 346-53.

74. Ozao-Choy J, Ma G, Kao J, Wang GX, Meseck M, Sung M, et al. The novel role of tyrosine kinase inhibitor in the reversal of immune suppression and modulation of tumor microenvironment for immune-based cancer therapies. Cancer Res (2009) 69(6):2514-22. doi:10.1158/0008-5472.CAN-08-4709 
75. Xin H, Zhang C, Herrmann A, Du Y, Figlin R, Yu H. Sunitinib inhibition of Stat3 induces renal cell carcinoma tumor cell apoptosis and reduces immunosuppressive cells. Cancer Res (2009) 69(6):2506-13. doi:10.1158/00085472.CAN-08-4323

76. Cao M, Xu Y, Youn J, Cabrera R, Zhang X, Gabrilovich D, et al. Kinase inhibitor Sorafenib modulates immunosuppressive cell populations in a murine liver cancer model. Lab Invest (2011) 91(4):598-608. doi:10.1038/labinvest. 2010.205

77. Ko JS, Zea AH, Rini BI, Ireland JL, Elson P, Cohen P, et al. Sunitinib mediates reversal of myeloid-derived suppressor cell accumulation in renal cell carcinoma patients. Clin Cancer Res (2009) 15(6):2148-57. doi:10.1158/1078-0432.CCR$08-1332$

78. Abe F, Younos I, Westphal S, Samson H, Scholar E, Dafferner A, et al. Therapeutic activity of sunitinib for Her2/neu induced mammary cancer in FVB mice. Int Immunopharmacol (2010) 10(1):140-5. doi:10.1016/j.intimp.2009.09.023

79. Chen M-L, Yan B-S, Lu W-C, Chen M-H, Yu S-L, Yang P-C, et al. Sorafenib relieves cell-intrinsic and cell-extrinsic inhibitions of effector $\mathrm{T}$ cells in tumor microenvironment to augment antitumor immunity. Int J Cancer (2013) 134(2):319-31. doi:10.1002/ijc.28362

80. Kujawski M, Zhang C, Herrmann A. Targeting STAT3 in adoptively transferred T cells promotes their in vivo expansion and antitumor effects. Cancer Res (2010) 70(23):9599-610. doi:10.1158/0008-5472.CAN-10-1293

81. Finke JH, Rini B, Ireland J, Rayman P, Richmond A, Golshayan A, et al. Sunitinib reverses type-1 immune suppression and decreases T-regulatory cells in renal cell carcinoma patients. Clin Cancer Res (2008) 14(20):6674-82. doi:10.1158/1078-0432.CCR-07-5212

82. Adotevi O, Pere H, Ravel P, Haicheur N, Badoual C, Merillon N, et al. A decrease of regulatory $\mathrm{T}$ cells correlates with overall survival after sunitinib-based antiangiogenic therapy in metastatic renal cancer patients. J Immunother (2010) 33(9):991-8. doi:10.1097/CJI.0b013e3181f4c208

83. Nagai H, Mukozu T, Matsui D, Kanekawa T, Kanayama M, Wakui N, et al. Sorafenib prevents escape from host immunity in liver cirrhosis patients with advanced hepatocellular carcinoma. Clin Dev Immunol (2012) 2012:607851. doi:10.1155/2012/607851

84. Shrimali RK, Yu Z, Theoret MR, Chinnasamy D, Restifo NP, Rosenberg SA. Antiangiogenic agents can increase lymphocyte infiltration into tumor and enhance the effectiveness of adoptive immunotherapy of cancer. Cancer Res (2010) 70(15):6171-80. doi:10.1158/0008-5472.CAN-10-0153

85. Dirkx AEM, oude Egbrink MG, Castermans K, van der Schaft DWJ, Thijssen VLJL, Dings RPM, et al. Anti-angiogenesis therapy can overcome endothelial cell anergy and promote leukocyte-endothelium interactions and infiltration in tumors. FASEB J (2006) 20(6):621-30. doi:10.1096/fj.05-4493com

86. Terme M, Colussi O, Marcheteau E, Tanchot C, Tartour E, Taieb J. Modulation of immunity by antiangiogenic molecules in cancer. Clin Dev Immunol (2012) 2012:492920. doi:10.1155/2012/492920

87. Tartour E, Pere H, Maillere B, Terme M, Merillon N, Taieb J, et al. Angiogenesis and immunity: a bidirectional link potentially relevant for the monitoring of antiangiogenic therapy and the development of novel therapeutic combination with immunotherapy. Cancer Metastasis Rev (2011) 30(1):83-95. doi:10.1007/s10555-011-9281-4

88. Bose A, Taylor J, Alber S. Sunitinib facilitates the activation and recruitment of therapeutic anti-tumor immunity in concert with specific vaccination. Int J Cancer (2011) 129(9):2158-70. doi:10.1002/ijc.25863

89. Hodi F, O’Day S. Improved survival with ipilimumab in patients with metastatic melanoma. N Engl J Med (2010) 363(8):711-23. doi:10.1056/ NEJMoa1003466

90. Topalian S, Hodi F. Safety, activity, and immune correlates of anti-PD-1 antibody in cancer. N Engl J Med (2012) 366(26):2443-54. doi:10.1056/NEJMoa1200690

91. Kantoff P, Higano C. Sipuleucel-T immunotherapy for castration-resistant prostate cancer. $N$ Engl J Med (2010) 363(5):411-22. doi:10.1056/ NEJMoa1001294

92. Farsaci B, Higgins J, Hodge J. Consequence of dose scheduling of sunitinib on host immune response elements and vaccine combination therapy. Int J Cancer (2012) 130(8):1948-59. doi:10.1002/ijc.26219

93. Jaini R, Rayman P, Cohen PA, Finke JH, Tuohy VK. Combination of sunitinib with anti-tumor vaccination inhibits $\mathrm{T}$ cell priming and requires careful scheduling to achieve productive immunotherapy. Int J Cancer (2014) 134(7):1695-705. doi:10.1002/ijc.28488

94. Huang Y, Yuan J, Righi E, Kamoun WS, Ancukiewicz M, Nezivar J, et al. Vascular normalizing doses of antiangiogenic treatment reprogram the immunosuppressive tumor microenvironment and enhance immunotherapy. Proc Natl Acad Sci USA (2012) 109(43):17561-6. doi:10.1073/pnas.1215397109

95. Dall'Oglio MF, Sousa-Canavez JM, Tanno FY, Tiseo BC, Crippa A, Dos Reis ST, et al. Early experience with targeted therapy and dendritic cell vaccine in metastatic renal cell carcinoma after nephrectomy. Int Braz J Urol (2011) 37(2):180-6. doi:10.1590/S1677-55382011000200004

96. Bhatia S, Curti B, Ernstoff MS, Gordon M, Heath EI, Miller WH, et al. Recombinant interleukin-21 plus sorafenib for metastatic renal cell carcinoma: a phase 1/2 study. J Immunother Cancer (2014) 2(1):2. doi:10.1186/2051-1426-2-2

Conflict of Interest Statement: Simon Pernot, Julien Taieb, Magali Terme received research grant from Roche. Julien Taieb has advisory role in Roche. No potential conflicts of interest were disclosed by the other authors.

Received: 30 January 2014; accepted: 20 March 2014; published online: 02 April 2014. Citation: Voron T, Marcheteau E, Pernot S, Colussi O, Tartour E, Taieb J and Terme M (2014) Control of the immune response by pro-angiogenic factors. Front. Oncol. 4:70. doi: $10.3389 /$ fonc. 2014.00070

This article was submitted to Tumor Immunity, a section of the journal Frontiers in Oncology.

Copyright (C) 2014 Voron, Marcheteau, Pernot, Colussi, Tartour, Taieb and Terme. This is an open-access article distributed under the terms of the Creative Commons Attribution License (CC BY). The use, distribution or reproduction in other forums is permitted, provided the original author(s) or licensor are credited and that the original publication in this journal is cited, in accordance with accepted academic practice. No use, distribution or reproduction is permitted which does not comply with these terms. 